\title{
Ovarian Sex Cord-Stromal Tumor Associated with Peutz-Jeghers Syndrome
}

National Cancer Institute

\section{Source}

National Cancer Institute. Ovarian Sex Cord-Stromal Tumor Associated with Peutz-

leghers Syndrome. NCI Thesaurus. Code C40436.

A sex cord-stromal tumor that arises from the ovary in a patient diagnosed with PeutzJeghers syndrome. 